\title{
Experimental evaluation of the pseudotime principle for nonisothermal polymer flows
}

\author{
Yu, Kaijia; Rasmussen, Henrik K.; Skov, Anne Ladegaard
}

Published in:

Journal of Rheology

Link to article, DOI:

$10.1122 / 1.3610439$

Publication date:

2011

Document Version

Publisher's PDF, also known as Version of record

Link back to DTU Orbit

Citation (APA):

Yu, K., Rasmussen, H. K., \& Skov, A. L. (2011). Experimental evaluation of the pseudotime principle for nonisothermal polymer flows. Journal of Rheology, 55(5), 1059-1067. https://doi.org/10.1122/1.3610439

\section{General rights}

Copyright and moral rights for the publications made accessible in the public portal are retained by the authors and/or other copyright owners and it is a condition of accessing publications that users recognise and abide by the legal requirements associated with these rights.

- Users may download and print one copy of any publication from the public portal for the purpose of private study or research.

- You may not further distribute the material or use it for any profit-making activity or commercial gain

- You may freely distribute the URL identifying the publication in the public portal

If you believe that this document breaches copyright please contact us providing details, and we will remove access to the work immediately and investigate your claim. 


\title{
Experimental evaluation of the pseudotime principle for nonisothermal polymer flows
}

\author{
Kaijia Yu and Henrik Koblitz Rasmussen ${ }^{\text {a) }}$ \\ Department of Mechanical Engineering, Technical University of Denmark, \\ DK-2800 Kgs., Lyngby, Denmark \\ Anne Ladegaard Skov \\ Department of Chemical and Biochemical Engineering, Technical University \\ of Denmark, DK-2800 Kgs., Lyngby, Denmark
}

(Received 5 January 2011; final revision received 30 May 2011; published 20 July 2011)

\begin{abstract}
Synopsis
We have applied a series of start-up of uniaxial extensions to very high strain followed by stress relaxation. A potential temperature change was applied during the stress relaxation. We used two thermorheological simple polymers; a linear polystyrene and a branched low density polyethylene. Experiments performed with temperature changes during the stress relaxation were shown to be identical with isothermal ones in the "pseudotime," within the accuracy of the experiments. This verifies that the pseudotime approach seems to be the general basis for nonisothermal microstructural modeling for flow of polymers. The pseudotime is given as $\xi(t)=\int_{0}^{t} 1 / a_{T}\left(T\left(t^{\prime}\right)\right) d t^{\prime}$, where $a_{T}$ are the well established time-temperature superposition shift factors, calculated from the past temperatures (at time $t^{\prime}$ ) in a particle path (C) 2011 The Society of Rheology. [DOI: 10.1122/1.3610439]
\end{abstract}

\section{INTRODUCTION}

The importance of nonisothermal phenomena in the dynamics of polymers is generally accepted, as in almost all processing of soft materials the polymers experience nonisothermal conditions. Usually, in the manufacture of thermoplastic products, polymer pellets are melted and processed through a sequence of operations and at last they are cooled down to form the final product. Therefore, the nonisothermal history plays an important role and closely relates to the quality of the product. Nonisothermal conditions require that a polymer molecule experiences a significant temperature change within the maximal relaxation time of the molecule. Otherwise, the well established time-temperature superposition applies [Leaderman (1941); Schwarzl and Staverman (1952); Williams et al. (1955)]. The time-temperature superposition treats isothermal experimental data at different temperatures for so called "thermorheological simple" materials.

Theoretically, the attempt to develop the fundamental thermodynamics of nonisothermal polymeric fluids has been successful [Dressler et al. (1999)]. It allows development of thermodynamics consistent constitutive models based on microscopic theory for the

\footnotetext{
a) Author to whom correspondence should be addressed; electronic mail: hkra@mek.dtu.dk
} 
dynamics of the mesoscopic structures. This in itself does not establish the nonisothermal dynamics of the mesoscopic structures in polymeric fluid; a model is needed [Wiest (1988); Wiest and Phan-Thien (1988); Braun and Friedrich (1990); Peters and Baaijens (1997)]. Computational modeling on the molecular level may lead to a further understanding, but molecular dynamics on polymers is in its initial stages as long relaxation times present a computational restrain. The only widely used theory for the nonisothermal dynamics of polymers seems to be the pseudotime principle, consistent with basic microscopic theories [Crochet and Naghdi (1974); Wiest (1988)]. It is classically referred to as originating from Morland and Lee (1960). They introduced this principle for small linear deformations. The "pseudotime" $\xi$ is the material's "inter clock," which varies with the temperature. It is given as

$$
\xi(t)=\int_{0}^{t} 1 / a_{T}\left(T\left(t^{\prime}\right)\right) d t^{\prime}
$$

where $\xi(t)$ is the present pseudotime at the present time $t . a_{T}$ is the well established timetemperature superposition shift factor [Leaderman (1941); Williams et al. (1955)]. $a_{T}$ is found from the past temperatures (at time $t^{\prime}$ ) on a particle path. The pseudotime assumption is widely debated [Dressler et al. (1999)] due to its simplicity but, nevertheless, serves as the basis of most modern nonisothermal simulations for polymer processing [Luo and Tanner (1987); Barakos and Mitsoulis (1996); Marín and Rasmussen (2009)].

Here in the present study, the purpose is to verify whether the pseudotime approach is the basis for microstructural modeling for flow of polymers in general, or if the pseudotime is too simple to explain the dynamic of the mesoscopic structures. Very few experimental papers have been published previously on this subject [McGuirt and Lianis (1969); Matsui and Bogue (1977a, 1977b)] and with contradicting conclusions. These studies were all based on the theoretical assumption that the time and strain separability, well established for small linear deformations [Ferry (1970)], should be valid outside linear deformations. Several more recent experimental studies [Wagner et al. (2005); Rasmussen et al. (2009)] have shown that this is definitely not a correct assumption. It is, therefore, particular important to ensure that the experimentally approach do not contain any theoretical restrictions on the underlying microscopic theory, except the pseudotime principle itself. Our approach is to apply a constant strain rate uniaxial elongation in the entangled regime to very high strain values, follow by a full stress relaxation. The uniaxial elongation is performed at the same temperature where the temperature change is applied during the stress relaxation. Therefore, experiments performed at different temperatures should be identical in the pseudotime $\xi(t)$, if the pseudotime approach is correct.

\section{METHODOLOGY AND MATERIALS}

In elongation of entangled polymer melts to high strain values followed by stress relaxation, a ductile failure commonly appears in the sample, either during the extension or the following relaxation [Wang et al. (2007)]. A ductile necking during the measurements leads to loss of sample homogeneity and eventually to a breakage. It is limiting the use of most extensional rheometers, where an exception seems to be the filament stretch rheometer (FSR), which has shown the ability to prevent the ductile failure [Bach et al. (2003b); Nielsen et al. (2008)].

Here, we followed the experimental procedure from Nielsen et al. (2008). The extension and following relaxation of the polymer melts are performed using the FSR [Bach 
et al. (2003a)]. A cylindrical polymer sample (with initial radius $R_{i}=4.5 \mathrm{~mm}$ and height $L_{i}=2 \mathrm{~mm}$ or $L_{i}=2.5 \mathrm{~mm}$ ) was placed between two parallel plates, where the upper plate is moved upward during the experiment, while the bottom plate remains stationary. Before measurement, the sample was allowed to relax in the liquid state removing any residual stress to ensure a random configuration of the polymer chains. During the elongational experiment, a laser micrometer samples the mid diameter of the extended filament while a force cell measures the synchronous force at the end plate. The diameter data are sent directly to a controller that produces a signal to the motor moving the end-plates. This control loop ensures that the central radius of sample decreases exponentially with time as $R(t)=R_{0} e^{-\dot{\varepsilon}_{0} t / 2}$, where $R_{0}$ is the initial sample radius and $\dot{\varepsilon}_{0}$ is the strain rate. The relevant extensional strain is a local measurement based on the midfilament radius as the Hencky strain $\epsilon=2 \ln \left(R_{0} / R(t)\right)$. The deviation between expected and real radius is generally below $1 \%$ when the elongation rate is kept lower than $0.1 \mathrm{~s}^{-1}$. To achieve controlled relaxation, the radius at the centre of the sample was maintained constant by continuously controlling the movement of the end-plates as described in the work by Nielsen et al. (2008).

At small initial aspect ratios $A_{i}=L_{i} / R_{i}$, an extra shear contribution adds to the measured elongational force during the start-up of the flow [Spiegelberg et al. (1996)]. At higher strains, the deviations from ideal extension diminish [Kolte et al. (1997)]. After the extension experiment is complete, the measured radius $R(t)$ and force $F(t)$ are used to calculate the tensile stress as

$$
\sigma_{z z}-\sigma_{r r}=\frac{F(t)+m_{1} g / 2}{\pi R(t)^{2}} \cdot \frac{1}{1+\left(R(t) / R_{\mathrm{i}}\right)^{10 / 3} \cdot \exp \left(-A_{\mathrm{i}}^{3}\right) /\left(3 A_{\mathrm{i}}^{2}\right)},
$$

where the effect of the additional shear have been reduced by a correction factor from Rasmussen et al. (2010). It theoretically ensures that the initial true elongational stress will stay within $3 \%$ of this corrected stress if $A_{i} \geq 0.3$. Further, the measured force, $F$, is corrected by the weight of lower half of the polymer filament, $m_{1}$, and the gravitational acceleration $g$ [Szabo (1997)]. Very detailed discussions regarding the validity of the applied method can be found in Rasmussen et al. (2010). These [Szabo (1997); Rasmussen et al. (2010)] include both the theoretical continuous mechanical framework as well as detailed experimental procedures to achieve correct measurements. It is particular important to ensure that the sample should stay symmetric across the midfilament plane [Matallah et al. (2006)] as well as axisymmetric during extension [Rasmussen and Hassager (2001)].

We have used two polymers, a branched low density polyethylene (LDPE, Lupolen 3020D) and as in previous nonisothermal experimental investigations [McGuirt and Lianis (1969); Matsui and Bogue (1977a, 1977b)] a linear polystyrene (PS). Information about the melts are listed in Table 1. Both materials have been characterized in shear and extensional rheometry [Rasmussen et al. (2005); Rasmussen and Eriksson (2007)]. Particularly, both samples have been shown to follow the classical time-temperature superposition, e.g., they are thermorheological simple materials [Schwarzl and Staverman (1952)].

All previous studies using the FSR were isothermal. In the expansion to nonisothermal experiment, the environment temperature changes were recorded by thermocouples placed in different positions near the sample inside the heating chamber. Second, temperature variations were measured simultaneously with a thermocouple embedded within a thin layer of polystyrene and one without. The thickness of the polystyrene layer was comparable with the central diameter of polystyrene filament during relaxation. All thermometers gave the same reading during a temperature jump. The temperature variation is 
TABLE 1. Characterization of the polystyrene (Rasmussen and Eriksson, 2007) and polyethylene melts (Rasmussen et al., 2005).

\begin{tabular}{lcc}
\hline \hline & Polystyrene & Polyethylene \\
\hline Product number/product & CAS 0993-53-6 & Lupolen 3020D \\
Producer & Aldrich & DOW BASF \\
$M_{w}(\mathrm{~g} / \mathrm{mol})$ & 230000 & 300000 \\
$M_{n}(\mathrm{~g} / \mathrm{mol})$ & 60000 & 37500 \\
$M_{w} / M_{n}$ & 3.7 & 8 \\
$T_{g}\left({ }^{\circ} \mathrm{C}\right)$ & 94 & - \\
$T_{m}\left({ }^{\circ} \mathrm{C}\right)$ & - & 114 \\
\hline \hline
\end{tabular}

controlled in such accuracy that the temperature evolution profiles for the same temperature jump were consistently the same between different experiments. We further performed almost identical experiments changing only the initial radius of the sample. The measured stress data were, within the accuracy of the measurements, identical. These findings confirm that the samples can load the imposed temperature jump uniformly through their cross sections without time lags.

\section{A. Time-temperature superposition}

The time-temperature superposition shift factors of the melts were determined by shift of isothermal start-up as well as stress relaxation data at different temperatures at the FSR. This approach avoids any potential systematic error originating from the use of different equipments. For the polystyrene, a shift factor $a_{T}=4.5$ between 115 and $120{ }^{\circ} \mathrm{C}$ and $a_{T}=11$ between 120 and $130^{\circ} \mathrm{C}$ was determined. Shift factors for the temperature in the range from 115 to $130{ }^{\circ} \mathrm{C}$ were calculated by the William, Landel, and Ferry (WLF) equation [Williams et al. (1955)]. $\log _{10}\left(a_{T}\right)=-c_{1}^{0}\left(T-T_{a}\right) /\left(c_{2}^{0}+T-T_{a}\right)$, where $c_{1}^{0}=10.20, c_{2}^{0}=48.28^{\circ} \mathrm{C}, T_{a}=104.34^{\circ} \mathrm{C}$, and $T$ is the sample temperature in degree Celsius. Notice, due the mathematical dependency between the three parameters, two shift factors uniquely define the parameters in this equation. For the polyethylene, a shift factor of $a_{T}=6.4$ [Rasmussen et al. (2005)] between 130 and $170{ }^{\circ} \mathrm{C}$ was determined. Shift factor for the temperature in the range from 130 to $170{ }^{\circ} \mathrm{C}$ was fitted by the Arrhenius equation [Ferry $(1970)] \ln _{e}\left(a_{T}\right)=(\Delta \tilde{H} / R)\left(1 / T-1 / T_{a}\right)$, where $\Delta \tilde{H} / R=8291^{\circ} \mathrm{C}$. The temperature effect on stress was corrected with the equation $\sigma\left(T_{0}\right)=\sigma(T) \varrho_{0} T_{0} /(\varrho T) \approx \sigma(T) T_{0} / T$, where the temperature dependence of the density is neglected. The effect of the temperature on the density represents a stress correction of less than $3 \%$ for the LDPE melt and less than $1 \%$ for the polystyrene melt.

\section{B. Pseudotime}

In the present experiments, we define the zero of the time $(t=0)$ at the initiation of the extension. It then follows from Eq. (1) that the zero of the pseudotime is at $t=0$, e.g., $\xi(t=0)=0$. If we define our reference temperature as $T_{a}$ the pseudotime in Eq. (1) is given as

$$
\xi(t)=\int_{0}^{t} \exp \left(\frac{c_{1}^{0}\left(T\left(t^{\prime}\right)-T_{a}\right)}{\ln (10)\left(c_{2}^{0}+T\left(t^{\prime}\right)-T_{a}\right)}\right) d t^{\prime}
$$

for the WLF equation and 

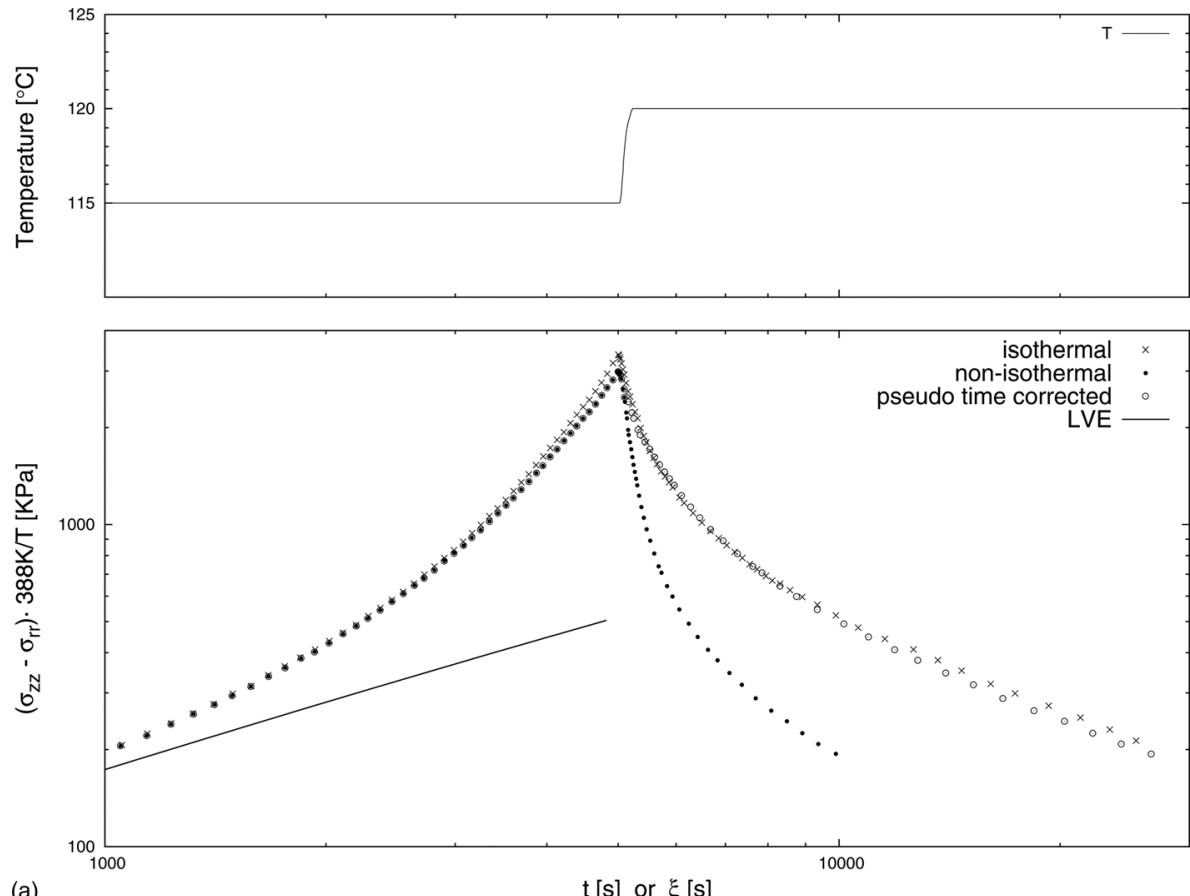

(a)

$\mathrm{t}[\mathrm{s}]$ or $\xi[\mathrm{s}]$
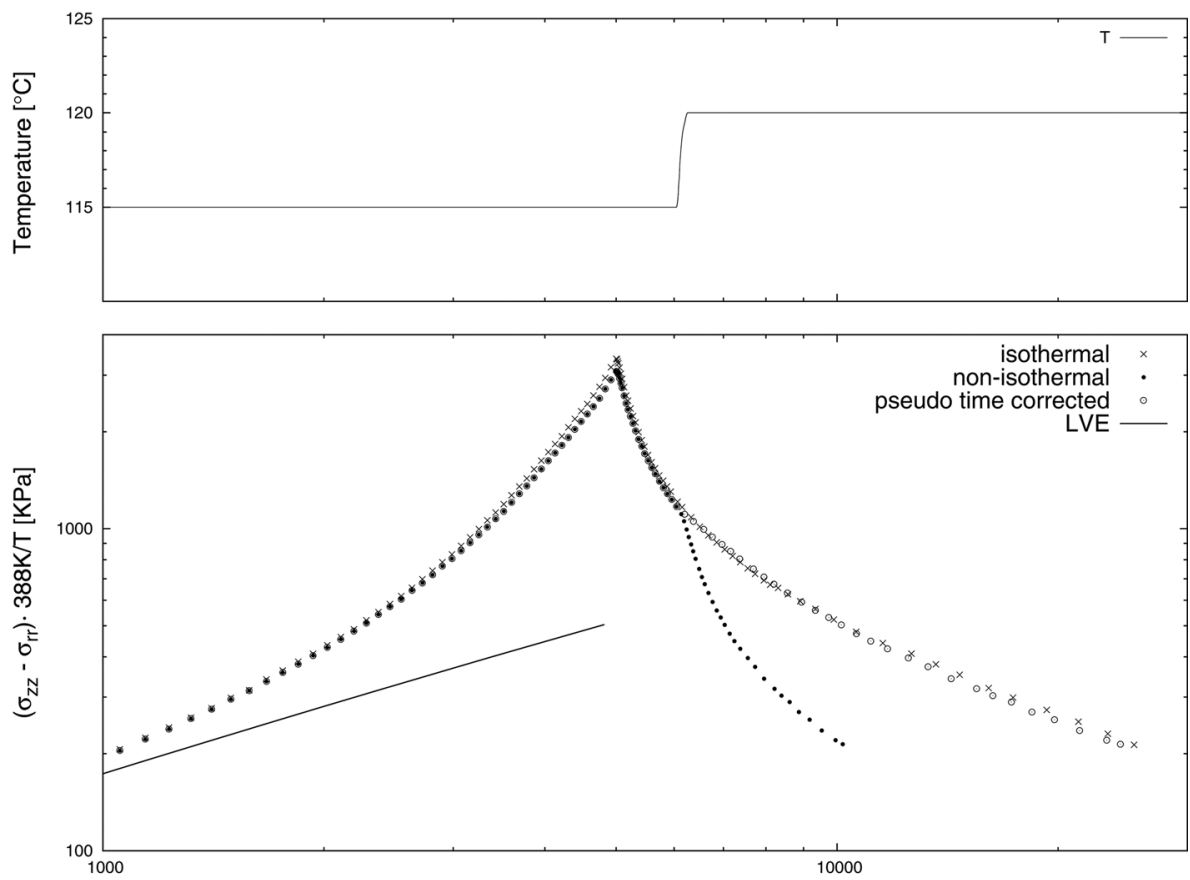

(b)

$t[s]$ or $\xi[s]$

FIG. 1. (a). Temperature (top) and extension stress (bottom) of start-up of extension $\left(\dot{\varepsilon}_{0}=0.0006 \mathrm{~s}^{-1}\right.$ at $115^{\circ} \mathrm{C}$ ) until $\varepsilon_{r}=3.0$ followed by relaxation of the polystyrene. The crosses $(\times)$ are isothermal measurements at $115{ }^{\circ} \mathrm{C}$ during the whole procedure, while the bullets $(\bullet)$ represent the experiment with the temperature change from 115 to $120{ }^{\circ} \mathrm{C}$ displayed in the above temperature curve. The bullets $(\bullet)$ are shifted to the circles $(\bigcirc)$ by the use of the pseudotime equation based on the evolution of the temperature. The lines in the bottom figures are the theory of linear viscoelasticity as obtained from Rasmussen and Eriksson (2007). (b): The same type of experiment as (a), with a delayed temperature changed. 


$$
\xi(t)=\int_{0}^{t} \exp \left(\frac{\Delta \tilde{H}}{R}\left(\frac{1}{T_{a}}-\frac{1}{T\left(t^{\prime}\right)}\right)\right) d t^{\prime}
$$

for the Arrhenius equation. The parameters are given in Sec. II A for the PS and LDPE melt, respectively. The temperature is measured as a function of the time [e.g., $T(t)$ ], but of course in discrete points in time. A simple linear interpolation is applied in between these discrete temperatures to get a continuous function of the temperature in time. This function is then inserted into Eq. (3) or (4) defining the pseudotime.

\section{RESULTS}

In all the experiments, the samples were stretched (isothermally) to the designated Hencky strain of $\varepsilon_{r}=3.0$ (the relaxation point) in the highly entangled regime [Rasmussen et al. (2005); Rasmussen and Eriksson (2007)]. The temperature change was imposed during the relaxation only. In relaxation, there is no flow in the material and, therefore, the stress changes due to the internal dynamics of the polymer. The results are depicted in Figs. 1-3. All presented data were based on an average of two independent measurements at the same experimental condition. The temperature evolution profiles (-) for the nonisothermal experiments are shown on the top of each of these figures. Note, the lines in the (bottom) Figs. 1-3 are based on the theory of linear viscoelasticity as obtained from Rasmussen et al. (2005) [using Rasmussen et al. (2000)] and Rasmussen and
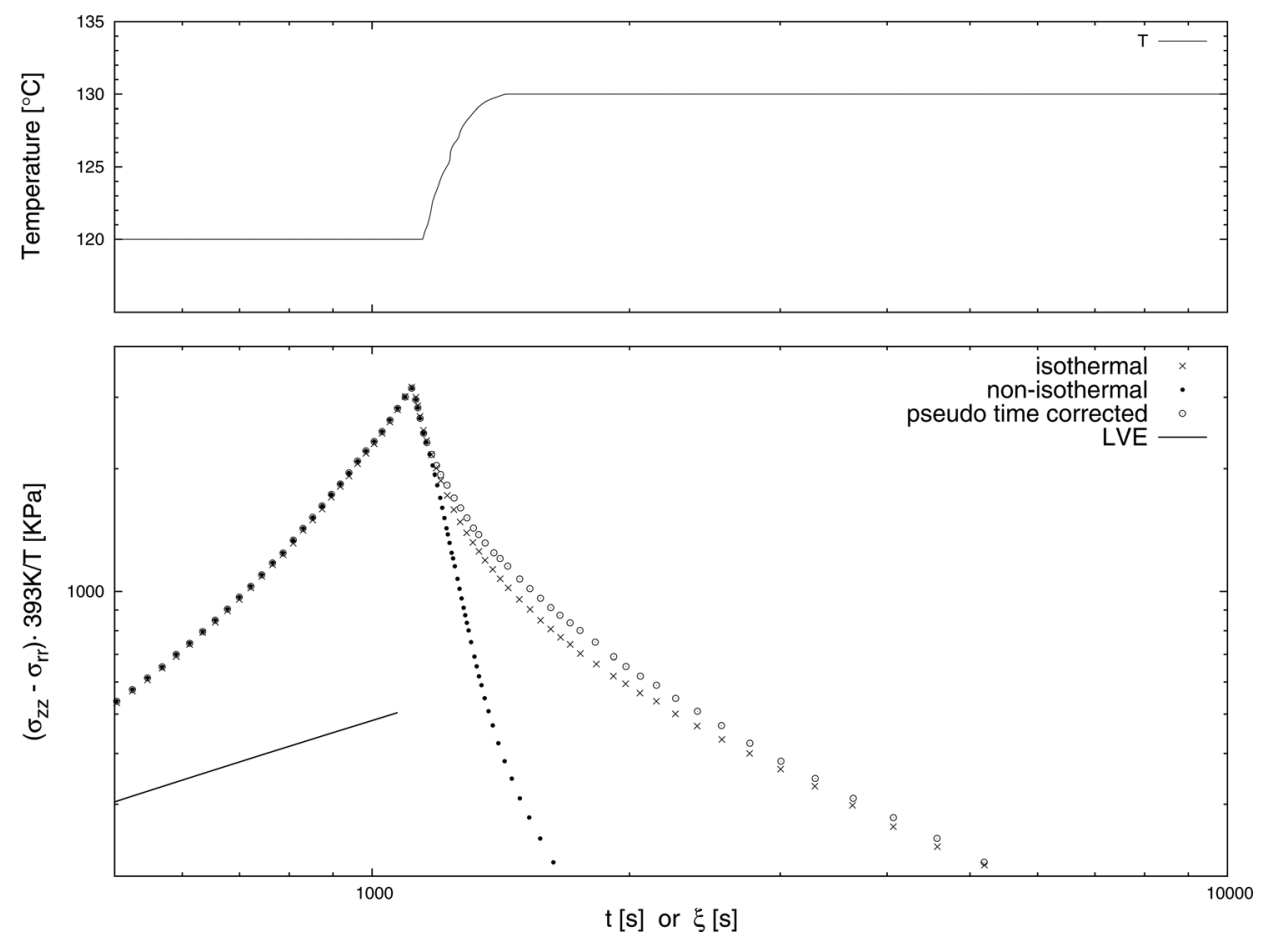

FIG. 2. Temperature (top) and extension stress (bottom) of start-up of extension $\left(\dot{\varepsilon}_{0}=0.0027 \mathrm{~s}^{-1}\right.$ at $120{ }^{\circ} \mathrm{C}$ ) until $\epsilon_{r}=3.0$ followed by relaxation of the polystyrene. The crosses $(\times)$ are isothermal measurements at $120^{\circ} \mathrm{C}$ during the whole procedure, while the bullets $(\bullet)$ represent the experiment with the temperature change from 120 to $130{ }^{\circ} \mathrm{C}$ displayed in above temperature curve. The bullets $(\bullet)$ are shifted to the circles $(\bigcirc)$ by the use of the pseudotime equation based on the evolution of the temperature. The line in the bottom figure is the theory of linear viscoelasticity as obtained from Rasmussen et al. (2005). 

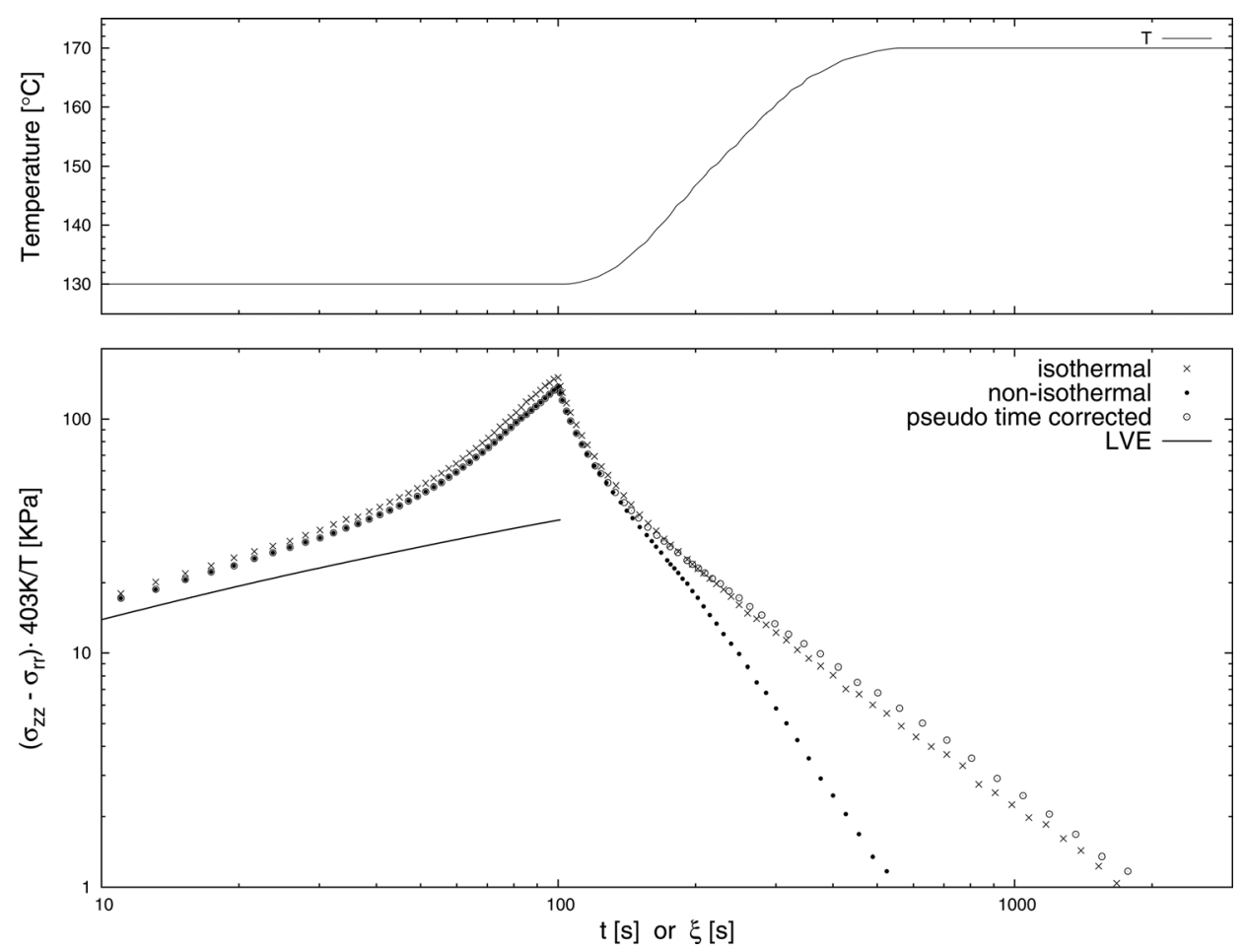

FIG. 3. Temperature (top) and extension stress (bottom) of start-up of extension $\left(\dot{\varepsilon}_{0}=0.03 \mathrm{~s}^{-1}\right.$ at $\left.130{ }^{\circ} \mathrm{C}\right)$ until $\varepsilon_{r}=3.0$ followed by relaxation of the LDPE. The crosses $(\times)$ are isothermal measurements at $130{ }^{\circ} \mathrm{C}$ during the whole procedure, while the bullets $(\bullet)$ represent the experiment with the temperature change from 130 to 170 ${ }^{\circ} \mathrm{C}$ displayed in above temperature curve. The bullets $(\bullet)$ are shifted to the circles $(\bigcirc)$ by the use of the pseudotime equation based on the evolution of the temperature. The line in the bottom figure is the theory of linear viscoelasticity as obtained from Rasmussen et al. (2005).

Eriksson (2007). These are identical with the corrected tensile stress at (very) small strains within the accuracy of the experiments.

The extensions of the polystyrene were performed isothermally at two temperatures of 115 and $120{ }^{\circ} \mathrm{C}$, with different strain rates of $\dot{\varepsilon}_{0}=0.0006 \mathrm{~s}^{-1}$ in Fig. 1 and $\dot{\varepsilon}_{0}=0.0027 \mathrm{~s}^{-1}$ in Fig. 2, respectively. These rates represent the same measurements according to the time-temperature superposition. The strain rate is 3000 times larger than the inverse of largest time constant (of about $10^{6} \mathrm{~s}$ at $120^{\circ} \mathrm{C}$ ) in the PS melt [Eriksson and Rasmussen (2005); Rasmussen and Eriksson (2007)]. Notice, before the extension of the polystyrene the sample was prestretched to an initial radius of $1.7 \mathrm{~mm}$, to reduce the transmitted force and thereby ensure adhesion between plate and sample.

In Fig. 1, the same temperature (-) jumps, from 115 to $120^{\circ} \mathrm{C}$, were imposed at two different points in time. At the top figures, the temperature jump was applied almost immediately after $(20 \mathrm{~s})$ the initiation of the relaxation. At the bottom figures, the temperature jump was imposed $1000 \mathrm{~s}$ after the initiation of the relaxation. The time of the nonisothermal measurements $(\bullet)$ was recalculated to the pseudotime at a reference temperature of $115^{\circ} \mathrm{C}(\bigcirc)$. This allows direct comparison with isothermal experimental data at $115^{\circ} \mathrm{C}(\times)$, which is shown at the figure as well. The duration of the temperature change in Fig. 1 was very short compared to the dynamic of the polymer. It was almost a ramp. A more gradual change in the temperature was applied in Fig. 2. In this case, the temperature (-) jump was imposed from a temperature of $120^{\circ} \mathrm{C}, 35 \mathrm{~s}$ after the start of relaxation. The same experimental methodology was applied on the LDPE melt in Fig. 3 
using a gradual temperature change from 130 to $170{ }^{\circ} \mathrm{C}$. The applied strain rate $\left(\dot{\varepsilon}_{0}=0.03 \mathrm{~s}^{-1}\right.$ at $130{ }^{\circ} \mathrm{C}$ ) is about 60 times larger than the inverse of the largest time constant (of $2100 \mathrm{~s}$ ) in the LDPE melt [Rasmussen et al. (2005)]. The time of the nonisothermal measurements $(\bullet)$ was recalculated to the pseudotime to a reference temperature of $130{ }^{\circ} \mathrm{C}(\bigcirc)$. This allows comparison with the isothermal experimental data at $130{ }^{\circ} \mathrm{C}$ $(\times)$. It is apparent that the nonisothermal data deviates from isothermal one when the temperature starts changing. All the modified curves under the pseudotime scheme overlap the corresponding isothermal experiment data quite well, within $10 \%$ experimental error.

\section{CONCLUSIONS}

In the use of the above experimental approach, the only theoretical restriction is the pseudotime principle itself. We have applied the experimental approach on two different polymers, which as well are structurally different; one linear and one branched. Further, we have used both gradual temperature changes as well as very fast changes (temperature ramps), of course relative to the dynamic of the polymer. The aforementioned agreement between isothermal and nonisothermal data after modified by pseudotime principle validates that the pseudotime principle seems to be the underlying nonisothermal theory for the dynamics of the mesoscopic structures in polymer melts.

\section{ACKNOWLEDGMENTS}

The authors gratefully acknowledge financial support from the "Direktør, dr. Techn. A.N. Neergaards og Hustrus Fond" foundation.

\section{References}

Bach, A., H. K. Rasmussen, and O. Hassager, "Extensional viscosity for polymer melts measured in the filament stretching rheometer," J. Rheol. 47, 429-441 (2003a).

Bach, A., K. Almdal, H. K. Rasmussen, and O. Hassager, "Elongational viscosity of narrow molar mass distribution polystyrene," Macromolecules 36, 5174-5179 (2003b).

Barakos, G., and E. Mitsoulis, "Non-isothermal viscoelastic simulations of extrusion through dies and prediction of the bending phenomenon,” J. Non-Newtonian Fluid Mech. 62, 55-79 (1996).

Braun, H., and C. Friedrich, "Dissipative behaviour of viscoelastic fluids derived from rheological constitutive equations,” J. Non-Newtonian Fluid Mech. 38, 81-91 (1990).

Crochet, M. J., and P. M. Naghdi, "On a restricted non-isothermal theory of simple materials," J. de Mécanique 13, 97-144 (1974).

Dressler, M., B. J. Edwards, and H. C. Öttinger, "Macroscopic thermodynamics of flowing polymeric liquids," Rheol. Acta 38, 117-136 (1999).

Eriksson, T., and H. K. Rasmussen, "The effects of polymer melt rheology on the replication of surface microstructures in isothermal moulding,” J. Non-Newtonian Fluid Mech. 127, 191-200 (2005).

Ferry, J. D., Viscoelastic Properties of Polymers, 2nd ed. (John Wiley \& Sons, New York, 1970).

Kolte, M. I., H. K. Rasmussen, and O. Hassager, "Transient filament stretching rheometer II: Numerical simulation," Rheol. Acta 36, 285-302 (1997).

Leaderman, H., "Textile materials and the time factor I. Mechanical behavior of textile fibers and plastics," Text. Res. J. 11, 171-193 (1941).

Luo, X.-L., and R. I. Tanner, "A pseudo-time integral method for non-isothermal viscoelastic flows and its application to extrusion simulation,” Rheol. Acta 21, 534-536 (1987).

Marín, J. M. R., and H. K. Rasmussen, "Lagrangian finite element method for 3D time-dependent non-isothermal flow of K-BKZ fluids,” J. Non-Newtonian Fluid Mech. 162, 45-53 (2009). 
Matallah, H., M. J. Banaai, K. S. Sujatha, and M. F. Webster, "Modelling filament stretching flows with strainhardening models and sub-cell approximations," J. Non-Newtonian Fluid Mech. 134, 77-104 (2006).

Matsui, M., and D. C. Bogue, "Non-isothermal rheological response during elongational flow," Trans. Soc. Rheol. 21, 453-468 (1977a).

Matsui, M., and D. C. Bogue, "Studies in non-isothermal rheology," Trans. Soc. Rheol. 21, 133-148 (1977b).

McGuirt, C. W., and G. Lianis, "Experimental investigation of non-linear, non-isothermal vis-coelasticity," Int. J. Eng. Sci. 7, 579-599 (1969).

Morland, L. W., and E. H. Lee, "Stress analysis for linear viscoelastic materials with temperature variation," Trans. Soc. Rheol. 4, 233-263 (1960).

Nielsen, J. K., H. K. Rasmussen, and O. Hassager, "Stress relaxation of narrow molar mass distribution polystyrene following uniaxial extension," J. Rheol. 52, 885-899 (2008).

Peters, G. W. M., and F. P. T. Baaijens, "Modelling of non-isothermal viscoelastic flows," J. Non-Newtonian Fluid Mech. 68, 205-224 (1997).

Rasmussen, H. K., A. G. Bejenariu, O. Hassager, and D. Auhl, "Experimental evaluation of the pure configurational stress assumption in the flow dynamics of entangled polymer melts," J. Rheol. 54, 1325-1336 (2010).

Rasmussen, H. K., A. L. Skov, J. K. Nielsen, and P. Laille, "Elongational dynamics of multiarm polystyrene," J. Rheol. 53, 401-415 (2009).

Rasmussen, H. K., J. H. Christensen, and S. J. Gottsche, "Inflation of polymer melts into elliptic and circular cylinders," J. Non-Newtonian Fluid Mech. 93, 245-263 (2000).

Rasmussen, H. K., J. K. Nielsen, A. Bach, and O. Hassager, "Viscosity overshoot in the start-up of uniaxial elongation of low density polyethylene melts," J. Rheol. 49, 369-381 (2005).

Rasmussen, H. K., and O. Hassager, "The role of surface tension on the elastic decohesion of polymeric filaments," J. Rheol. 45, 527-537 (2001).

Rasmussen, H. K., and T. Eriksson, "Gas displacement of polymer melts in a cylinder: Experiments and viscoelastic simulations," J. Non-Newtonian Fluid Mech. 143, 1-9 (2007).

Schwarzl, F., and A. J. Staverman, "Time-temperature dependence of linear viscoelastic behavior," J. Appl. Phys. 23, 838-843 (1952).

Spiegelberg, S. H., D. C. Ables, and G. H. McKinley, "The role of end-effects on measurements of extensional viscosity in filament stretching rheometers," J. Non-Newtonian Fluid Mech. 64, 229-267 (1996).

Szabo, P., "Transient filament stretching rheometer," Rheol. Acta 36, 277-284 (1997).

Wagner, M. H., S. Kheirandish, and O. Hassager, "Quantitative prediction of transient and steady-state elongational viscosity of nearly monodisperse polystyrene melts," J. Rheol. 49, 1317-1327 (2005).

Wang, Y., P. Boukany, S.-Q. Wang, and X. Wang, "Elastic breakup in uniaxial extension of entangled polymer melts," Phys. Rev. Lett. 99, 237801 (2007).

Wiest, J. M., “Time-temperature superposition in nonisothermal flow,” J. Non-Newtonian Fluid Mech. 27, $127-$ 131 (1988).

Wiest, J. M., and N. Phan-Thien, “Nonisothermal flow of polymer melts,” J. Non-Newtonian Fluid Mech. 27, 333-347 (1988).

Williams, M. L., R. F. Landel, and J. D. Ferry, “The temperature dependence of relaxation mechanisms in amorphous polymers and other glass-forming liquids,” J. Am. Chem. Soc. 77, 3701-3707 (1955). 